\title{
Chapter 8 \\ Creating Brighter Futures: Building Climate Leaders in the United States Through a Community-Focused Curriculum
}

\author{
Kathryn Bauman-Hill $\left(\mathbb{D}\right.$, Susan Dai $\mathbb{D}^{\mathbb{D}}$, and Arcadia Payne $\mathbb{D}$
}

\begin{abstract}
Throughout this volume, our co-authors focus on top-down education reforms. In this analysis, we take a different approach to education reform, instead focusing on the impact of translating a niche school-level curricular reform to expand to the systemic level. In this paper, we will argue for the need for an elementary climate change-focused curriculum and outline the components necessary to make such a program successful. We partnered with an independent school in the Washington, DC region to contextualize the process of building such a curriculum, with the additional benefit of the school being near political power. Nevertheless, the implications of our findings are applicable to a variety of contexts, including international ones. In our methodology, we examined best practices for creating a rigorous elementary curriculum that centers around climate change education and leadership development. We combined successful elements of climate change education programs, including participatory learning, interdisciplinary integration, and a focus on community-based learning. We utilized a logical framework to identify assumptions and risks, implementation steps, achievement indicators, and program evaluation tools, which helped us identify key considerations for scaling an elementary climate change curriculum.
\end{abstract}

K. Bauman-Hill ( $\square)$

Capitol Hill Day School, Harvard Graduate School of Education, 5602 Baltimore Ave,

Hyattsville, MD 20781, USA

e-mail: kbaumanhill@chds.org

S. Dai

Higher Ground Education, 20C Building 26, 999 Changshou Road, Jingan, 200040 Shanghai, China

A. Payne

Harvard Graduate School of Education, 6358 S 440 E, Murray, UT 84107, USA 


\section{Abbreviations}

FOR Friends of the Rappahannock

MUN Model United Nations

NGSS Next Generation Science Standards

SDG United Nations Sustainable Development Goals

\subsection{Introduction and Importance of Climate Change Education}

The previous chapters in this book address government-implemented education reforms - however, as any educator, student, or caregiver will confirm, policy changes are primarily felt within the school setting directly. While policies impact each level of our education systems globally, there is a noticeable gap in comprehensive, collaborative education regarding a subject that affects every person in our world: climate change. Symptoms like rising temperatures, ocean acidification, and sea level rise contribute to diminished agricultural capacity, exposure to health problems, and exacerbated weather events. According to the UN International Organization for Migration, the number of migrants fleeing environmental hazards may fall anywhere between 25 million to 1 billion by the year 2050 (Bassetti, 2019). Considering that both climate hazards and displacement of this scale would affect countries worldwide, it is increasingly clear that understanding and managing the adverse effects of climate change must be a priority within our education systems. This paper will contextualize development of an elementary climate change curriculum, delve into a review of existing climate education programs worldwide, form a program theory and implementation plan for a climate curriculum at the school level, and finally, discuss evaluation, impact, and scalability for a curriculum.

This chapter specifically examines the likelihood of developing climate change curriculum for elementary schools in the United States. It does so by exploring the design, implementation, and evaluation of climate change curricula, which are applicable lessons to any context. Climate change is considered a controversial topic in the United States, with discourse and action driven by political beliefs and party rhetoric. The United States formally pulled out of the Paris Agreement under the Trump Administration and have recently rejoined it with the support of the Biden Administration. Due to the depth of the renewed commitment of the United States to resolve climate change concerns, creating a younger generation aware of the effects of climate change who can create innovative solutions is essential. Schools have a critical role in educating students on this issue. Ensuring that students are exposed to climate change concepts at an early age is a crucial step in raising awareness and developing future leaders invested in climate change concerns.

To this end, by integrating climate change education within school systems, schools can highlight environmental protection as a core value and reinforce habits in 
students that drive systemic change by instilling stewardship, climate change awareness, and leadership in students. Using the concept of adaptive change, through which we intend to uplift climate change in the values and habits of students and their families, we argue that this change is appropriate and doable through the introduction of a community-focused climate change leadership curriculum.

This paper focuses on school systems in Washington, DC. The location was chosen for two different reasons: first, due to the team's familiarity with education systems and independent schools in the region, and second, its designation as the national capital, and thus the heart of U.S. political decision-making, including issues such as climate change. Through our analysis, we have determined that a targeted response through participatory, climate-focused elementary school curricula is needed. Acknowledging the gaps in existing school curricula helps to create a robust, substantive curriculum that positions students to be prepared for leadership roles. We have identified numerous benefits in utilizing an education response framed in critical, collaborative learning and other twenty-first century skills. Not only will students develop knowledge and tools to contribute to climate justice and mitigation of climate risks in Washington, DC, but students will gain skills that build confidence in navigating media, government, the corporate sector, and individual engagement. Additionally, elementary school students will learn the importance of a climate-oriented mindset to inform their future education and professional experiences. The curriculum will be based on Next Generation Science Standards (NGSS) as well as certain United Nations Sustainable Development Goals (SDGs), to emphasize moral and civic responsibility. In the long-term, this sets up Washington, DC's future leaders to take definitive action towards mitigating climate risks. While we do focus on the context of Washington, DC in this paper, the lessons and implications of implementing community-focused climate change education for elementary students are applicable for scaling in countries worldwide. Students who practice leadership grounded in empathy and social responsibility become leaders grounded in empathy and social responsibility.

\section{Part I}

\subsection{Local Context}

In this section, we explore water-related issues caused by rising temperatures in local contexts. With several rivers, creeks, and streams in its jurisdiction, the general Washington, DC region is more susceptible to flooding from storms, tidal surges, and sea level rise (Chesapeake Bay Foundation, 2020; Climate Central, 2014; Samenow, 2014). Increasing temperatures and precipitation contribute to flooding potential both in Washington, DC and in the Chesapeake Bay area, approximately 30 miles away (District of Columbia, n.d.; National Ocean Service, 2020). Land use by humans through farming and suburban sprawl, along with temperature changes, have directly 
impacted the water quality throughout the whole watershed (Maloney et al., 2020; Najjar et al., 2010; Orth et al., 2017). The wetlands that outline the Chesapeake Bay are a rich environment for many life forms within the ecosystem. Numerous factors affect the delicate balance of these wetlands (Kirwan \& Megonigal, 2013). An increase in population has created more risks for the land, animals, and plants. Water quality and storm runoff affect wetlands and streams, influencing the animal life within the waterways in the surrounding Chesapeake Bay region (Watts et al., 2019). Fish, shellfish, and submerged aquatic vegetation are affected by similar factors as the wetlands, leading to immense potential for disrupting the watershed ecosystem (Najjar et al., 2010; Orth et al., 2017).

In addition to changing the ecosystem, climate change will continue to disturb industry, exacerbate storms, and harm human health. Declines in coastal biodiversity decimate fishing and aquaculture industries and the food supply (Chesapeake Bay Foundation, 2020; U.S. Global Change Research Program, 2018). Sea level rise in Washington, DC is already affecting businesses adjacent to the city through persistent flooding (Fenston, 2019; U.S. Global Change Research Program, 2018). Furthermore, there has been a shift in housing as island residents within the Chesapeake Bay are forced to leave the region as the islands became uninhabitable (Arenstam et al., 2006; Leatherman et al., 1995). It is only a matter of time before climate change pushes these problems far enough to mobilize society to directly respond to these dire circumstances.

\subsection{Systematizing Innovation in Climate Change Education}

We recognize that introducing new curricula into school systems without assessing the capacity for adaptation and scalability can have dire impacts on curriculum development. When we envisioned a climate curriculum with a leadership focus, we wanted to partner with an institution that not only would benefit from a program such as ours, but also was willing to sponsor a pilot effort to incorporate climate change education in their existing curriculum. We chose an independent Pre-KGrade12 school as our partner institution due to its philosophy of learning through discovery, exploration, and active engagement, which aligned well with our projected curriculum.

Independent schools and charter schools often have more autonomy and mutability in their curricular decisions, and thus promote themselves as incubators of innovation (Stuart et al., 2017). However, even in many innovative school environments, curricula are still largely focused on environmental studies rather than climate change. We encourage education leaders to utilize these independent school models to pilot innovative curricula, including climate change education, in such environments - thus providing a context-based view of the impacts of climate change on local communities. This could include convincing a network of independent schools to pilot innovative climate change curricula together, therefore representing a test 
of the scalability potential and relevance of systems-change approaches of such curricula.

From Reimers' five perspectives for educational change, we recognize the need to develop skills to address climate issues using an institutional lens (Reimers, 2020). In interviewing science teachers at a partner school in Washington, DC, it was evident that curriculum from Pre-K to Grade 6 does not cover enough specific or substantive knowledge about climate change, especially instruction that is tailored toward the urgent needs of the DC region, such as precipitation concerns, and sea level changes related to rising temperatures. As a result, our curriculum will cultivate an understanding of local climate change issues and the competencies needed to mitigate climate change in elementary students. Ensuring various points of entry begins to develop a trajectory of comprehensive understanding. Creating multiple opportunities for climate change touchpoints is also ideal (Reimers, 2021). Through four key actors (media, government, the corporate sector, and individual/community engagement) that embody institutional systems, students develop skills to take on leadership roles and build their civic identity in a collaborative and interactive manner.

In developing a successful curriculum, considerations must include how to shape mindsets on the importance of learning about climate change, and how to raise awareness on mitigation actions. For best results, climate change would be prioritized as an institutional goal throughout the school. This process requires a level of psychological awareness from both the student and the teacher. Ideally, the culture of the school supports the idea of environmental stewardship, and a focus on environmental education creates an entry point. Centering climate change issues in a developmentally appropriate way fosters a growth mindset for students towards the topic. Gaining support for a cohesive curriculum requires a political approach to mobilize homeroom teachers, science teachers, extracurricular club advisors, after-school coordinators, and administration. Creating professional development opportunities to enhance the understanding of teachers about concepts and issues related to climate change is crucial for its success, particularly since this age group is not traditionally targeted in climate change education (Reimers, 2020).

Aspects of adaptive change can shift ideas and mindsets within each of the five frames. Sharing facts and background information about climate change builds a sense of recognition and urgency about the topic. Developing an understanding of the beliefs of educators, parents, and students towards climate change can also indicate the "ripeness," or readiness to invest in the idea (Heifetz et al., 2009). To measure this readiness, we intentionally thought about how to gauge student, family, and teacher attitudes throughout the program, which we pursued by distributing surveys to stakeholders. Framing the importance of teaching climate change as an ethical issue builds a sense of moral responsibility and may connect the action-oriented aspect of the curriculum to a school's mission. Building a core group of individuals who are invested in the importance of teaching climate change has two advantages. First, they can influence others who may not see the essential nature of creating a comprehensive curriculum across the school. Secondly, they can begin to share responsibility regarding the importance of educating others on various aspects of 
climate change knowledge, competencies, and dispositions. Developing an awareness of dissenting opinions is critical in maintaining forward momentum. Engaging those with opposing views by creating a space to share ideas and concerns develops an open dialogue, with the potential to raise the overall awareness on climate change (Heifetz et al., 2009). Consistent reflection helps to realign priorities and conversations, which allows systems to build the capacity necessary to address climate change issues.

\subsection{Analysis of Current Climate Education Curriculum Models}

In building our curriculum, we wanted to investigate best practices in existing climate curriculum models. A few major themes arose throughout our research which served to foster successful climate change curricular initiatives: integration across subject areas, presenting a balance of science facts with optimism, experiential learning activities, developing a web of support, connecting to the local community, using a variety of media and literary entry points, and proper teacher training to remove barriers of lack of knowledge about climate change. From this information, we decided to further examine participatory, community-focused, and interdisciplinary learning applicable to our local context to include within our curriculum.

When investigating climate change curriculum for upper elementary school students, it is important to consider the developmental appropriateness of the content. Current science curricula in the US includes science concepts that assume a higher level of understanding which many youths have not yet acquired (Monroe et al., 2019). By supplementing the current United States science learning frameworktitled the Next Generation Science Standards (NGSS)—with social science concepts developed through the UN Sustainable Development Goals (SDGs), climate change curriculum becomes more accessible to younger students. A connection to global climate change is implied within the elementary level of the NGSS, as students explore the definition of climate, natural disasters, and human impact on the earth, although it is not explicitly stated as a standard until the middle school level (Next Generation Science Standards, n.d.). Extending beyond topics such as weather to systems thinking provides a means to support a developmentally appropriate manner of student acquisition of information, fostering a deeper level of understanding and a richer knowledge base (Roychoudhury et al., 2017; Van Zee et al., 2016). Through systems focused learning, students can see the scope of an issue more deeply and perform targeted problem-solving within various levels of the system. As effects of climate change veer into ideas supported in the SDGs-such as public health, human rights, and human welfare, particularly in marginalized communities - there are opportunities to base climate curriculum in the social science realm (Perkins et al., 2018; Seeley, 2019; Yorio, 2019). The SDGs provide an accessible entry point 
for students of all ages, thus creating a mindset of stewardship in the next generation by investing in future oriented thinking (Monroe et al., 2019; Holdsworth, 2019). The SDGs help move the students' awareness from a local to a global level and connect climate change issues to human rights (UN Environment Programme, n.d.). They have potential to be driving agents for new reforms, such as good practices designed by schools and organizations. By identifying problems first and then investigating solutions, students can make marked change in their communities (Sustainable Development Goals, n.d.).

\subsubsection{Community-Focused Learning}

Connecting a climate curriculum to its cultural context provides an opportunity to build investment in local issues, as well as to improve the lives of those affected in a region (Perkins et al., 2018; Monroe et al., 2019). When students start to examine issues locally, they can transfer them incrementally into a broader global understanding (VanZee 2016). Perkins et al. (2018) compared the pedagogy in five countries (Mexico, Brazil, Saudi Arabia, Germany, and China) towards climate change. Their findings prioritized each area's highest environmental needs to be integrated into the curriculum initiated from the 2015 Paris Agreement on climate change. Brazil focuses on greenhouse gases, global warming, and cultural differences, while China commits to innovative teaching methods, inquiry-based learning, and increasing personal motivation and awareness in students. Germany prioritizes understanding the cause-and-effect relationships resulting from climate change, thus encouraging lifestyle adjustments. Mexico highlights explaining the social factors surrounding climate change, while encouraging critical thinking and a multi-disciplinary approach to problem solving the issues. Saudi Arabia focuses on fostering classroom debate and enhancing critical thinking skills to raise awareness about climate change issues and policies (Perkins et al., 2018). Although each of these countries differ in approaches, a common theme is critical analysis and mitigation through activism (Perkins et al., 2018). Interactive, inquiry-based, and participatory curriculum most effectively develops a thoughtful approach to student agency (Perkins et al., 2018; Monroe et al., 2019; Roychoudhury et al., 2017).

Incorporating local environments and climate issues into a school experience is also an effective form of education for primary students, because it is familiar and accessible. Community-based pedagogy further helps young people to see what is valuable and worth preserving in their home communities (Smith \& Sobel, 2014). As shown in other chapters in this book, such as reforms in India and Senegal, community-driven initiatives allow stakeholders in the community to experience the growth and development of students in the area. Even though some sources note that the public tends to be poorly involved and poorly informed about impacts of daily actions in relation to climate change (Jamal \& Watt, 2011), we take lessons from Chaps. 2 and 6 about the efficacy of community-driven reforms. 
We found two best practices of using community-based pedagogy in addressing environmental and climate issues; the first is Sunnyside Environmental School, a K-8 school in Portland, Oregon, and the second is the Mountain Air Program in Canmore, Canada. The Sunnyside Environmental School has created educational experiences directed towards this end since the fall of 1995. School leaders initially envisioned schools to be more responsive to students' needs for social interaction, hands-on learning experiences, and the opportunity to situate themselves in both the human and the natural contexts of their own lives. Graduates of the program are drawn to environmental fields and display a willingness to become politically involved. Similarly, the Mountain Air Program in the mountain resort of Canmore, Canada, involving schoolchildren and businesses to tackle clean air impacts from local transport, including taxis. Students work with an anti-idle program to produce a communication campaign, including radio segments and visual media, which develop students' participation in community affairs and their proficiency with engaging in media (Jamal \& Watt, 2011). Both programs are model efforts because they show the link between climate-focused programs and students' willingness to participate through the four sectors, including government, corporations, community action, and media.

\subsubsection{Participatory Learning}

In this section, we explore the efficacy of participatory learning in climate change curricula. Through discussions, experiential learning, role plays and other collaborative interactions, a constructivist model develops students' knowledge base (Monroe et al., 2019). By actively participating in the learning process by debating ethical issues, students gain argumentation skills and slowly begin to take action to mitigate climate change (VanZee, 2016; Monroe et al., 2019). Such skills have the benefit of preparing students for future citizenship (Holdsworth, 2019) and to become politically active (Yorio, 2019). Erbil and Kocabas (2018) note that although democratic attitudes are not prioritized at an elementary level, cooperative learning methods enhance the understanding of democracy and develop responsible citizenship skills.

Multiple countries and organizations have extended learning for students to apply these skills outside the classroom. We studied two participatory approaches focused on experiential learning in nature and leadership development through a Model United Nations (MUN) framework. There are primary and secondary schools and educational programs worldwide that incorporate nature-based solutions in student learning; for example, the Green Project Hub at Bali's Green School requires students to follow a set of principles, including incorporating the SDGs and utilizing design thinking and project management skills to address a problem in the world (The Green School, 2020). The city of Genk, Belgium, uses three community gardening programs to engage local stakeholders and partner with education environments to build eco-friendly gardens and bolster bee populations (Kabisch et al., 2017). Within Washington, DC and the Chesapeake Bay, high school students from the Glenn's 
Campus of the Chesapeake Bay Governor's School partnered with Friends of the Rappahannock (FOR) in 2015 to install riparian restoration projects in Urbanna, VA (Friends of the Rappahannock, 2015). With the help of FOR and Ready Reef Inc., students installed concrete oyster reefs in the Rappahannock River. Over time, they monitored shorelines and reinforced the banks of the river to control erosion and reestablish wetland vegetation (FOR, 2015). Creating artificial oyster reefs has been a successful intervention in protecting riparian environments and increasing oyster populations in the bay (Chesapeake Bay Foundation, 2020).

When considering where students might apply leadership skills in conversation about pressing climate issues, we joined our peers from Chap. 7 of this book (OC Climate Curriculum) to evaluate Model United Nations (MUN) curricula as an avenue for student leadership development. The MUN blends case-based instruction and investigation with aspects of problem-based learning (McIntosh, 2001). It also has been one of the most popular experiential learning methods. The lowest estimates show that roughly 400,000 students at all educational levels participate in simulations of the UN in more than 400 conferences held in 35 countries around the world (Crossley-Frolick, 2010). According to the learning outcomes assessment of the MUN, first-time participants increased their knowledge of the UN and the topic discussed in the model, developed a realistic orientation towards international relations, and emphasized the importance of individual agency in world affairs (Jesuit \& Endless, 2018). Expanding a simulation-based program for elementary students like MUN would help younger students build global awareness and understand their role in larger systems.

\subsubsection{Interdisciplinary Learning}

Current interdisciplinary curricula leverage standards and cross-cutting concepts within subjects to apply climate and environment focused content within different fields. Few national curricula fully integrate climate change across integrated subject areas, but curricula like the NGSS and the Australian Curriculum both utilize multi-disciplinary skills and cross-cutting concepts to encourage connecting science learning to language and literature, mathematics, writing, and other subjects. Of notable importance is that the NGSS do not address sustainability and climate change specifically at the elementary level, but rather focus on Earth processes. In the curricula currently, third graders describe world regional climate and create a design solution to mitigate weather hazards. Fourth graders use the scientific process to better understand weathering and erosion, how fuel extraction impacts the environment, and create mitigation strategies for "earth processes" on humans. Fifth graders investigate water distribution and how communities rely on scientific evidence for environmental protection (Next Generation Science Standards for States-by-States, n.d). In June 2020, the state of New Jersey adopted an interdisciplinary curriculum specifically connected to climate change from grades K-12. In it, third graders investigate patterns of change in climate and weather conditions as 
well as cause and effect in natural disasters, fourth graders explore mitigation of natural hazards, and fifth graders examine human impact on the Earth. Here, math and literacy standards are suggested entry points for building the skillsets necessary to understand climate change (State of New Jersey Department of Education, 2020). The Australian Curriculum explicitly states the importance of sustainability: "All Australian Curriculum learning areas have a potential to contribute to the sustainability cross-curriculum priority" (ACARA, 2020). We found curricula from independent groups and nonprofit organizations like Climate Generation, Green Schools National Network, and the World Wildlife Foundation. Each set of lessons spans multiple grades and subject areas, and lessons are meant to supplement prescribed curriculum (even though the lessons are standards-based).

Using various formats to introduce climate change creates multiple opportunities for students to engage with the issues. Using a humanities- and social sciences-based approach brings in a human connection to the study of abstract scientific concepts. Personal stories and narratives present an opportunity to explore other perspectives and gain a deeper understanding of how the issues impact others and build a layer of concern. Additionally, creating a supportive community through educators, peers, non-profit organizations, local groups, and families builds collective knowledge, and supplies a cohesive environment for promoting climate change engagement (Siegner \& Stapert, 2020). Providing a multi-media approach through various means (non-fiction, TED talks, documentaries, climate fiction, children's literature, etc.) cultivates a broader eco-awareness in students (Pellet, 2020). Through these differentiated entry points, knowledge about climate science is transmitted to the students, and a balance of positive messaging is necessary to counteract the realities of climate concerns (Bigelow, 2020). When educators are well-versed in climate science and have adequate training and resources, they are viewed as trusted partners in developing foundational knowledge in their students (Foss \& Ko, 2019; Siegner \& Stapert, 2020).

\subsection{Integrating Best Practices}

When developing a curriculum on climate change for third through fifth grades, examining how to heighten investment is a key feature. The NGSS, which have a focus on systems, allows students to build a deeper awareness of the interrelated aspects of climate change. Additionally, students at this age have a heightened sense of fairness, so human rights are a meaningful entry point. Individual engagement, government, media, and corporations/community are all aspects to leverage when building investment in mitigating climate change (Watts et al., 2019). Deepening knowledge is an essential first step of helping students understand the why behind climate change, thus setting the stage for student action.

The SDGs provide a moral compass to guide student engagement within the instruction of social sciences when examining climate change. The overarching idea of climate action (SDG 13) becomes more comprehensive when supplemented with 
other SDGs, such as affordable clean energy, sustainable communities as well as responsible production, management, and consumption (United Nations n.d). Understanding the deep health effects of climate change caused by the inter-relationship between people and the land can inspire students to recognize the personal impact of climate change issues. By aligning these ideas with local contexts, students-alongside communities and corporate actors - are better able to see the personal relevance of regional issues related to climate change. We saw evidence of this through community organizations involving students in riparian restoration in the Chesapeake Bay (FOR, 2015). As students become more adept in recognizing community concerns, connecting with organizations that are remedying local climate topics can launch an urgency in why climate change should be addressed. Examining these ideas through participatory and collaborative learning opportunities enhances student engagement, as they discuss the greater issues and participate in simulations to demonstrate local outcomes of climate change. Students will build a foundation of knowledge and skills to apply towards becoming local agents of change. With a focus on community activism, students will be empowered to more direct and targeted action-a leverage point which is often missing in many climate change curriculums (Siegner \& Stapert, 2020).

Addressing climate change issues requires critical engagement in four domains: the media, government, corporate sector, and individual engagement (Watts et al., 2019). Therefore, in addition to learning scientific knowledge, students need to build their civic identity and understand their responsibility to community and people. International programs, including those mentioned in China, Mexico, Saudi Arabia, and Australia, advance beyond the US in implementing participatory, community-focused, and interdisciplinary climate curricula. Therefore, we employed community-based pedagogy and simulations like MUN in our curriculum to build civic identity for elementary school students. Some critics think simulations such as MUN only promote surface learning without substantive depth (Haack, 2008; McIntosh, 2001). Yet supporters have found students gained an understanding of international relations, and thus emphasize the importance of individual agency in shaping world affairs (Jesuit \& Endless, 2018). Concept familiarity and basic task understanding works well for building global awareness and civic identity in elementary students (Haack, 2008). Middle childhood is a key time to build a foundation for future civic engagement, as children at this age begin to demonstrate more complex understandings and interactions with their social world (Eccles, 1999; White, 2012). Civic engagement can involve partnerships with community and corporate organizations, or opportunities for critical reflection or pushback on community movements and organizations as institutions.

From the level of local decisions regarding climate change, concepts can be extended to the government sector. The 2015 Paris Accord is a model of cooperative influence, which creates a heightened sense of necessity to remedy climate change. Examining how countries prioritize and work towards a common goal can inspire students to use decision making skills to highlight what local issues need to be addressed. Debate, especially through a simulation in the classroom, can help 
them understand the various perspectives between stakeholders within the community. Additionally, they can develop their own voice and agency within the context of a larger classroom framework of simulations like MUN (Jesuit \& Endless, 2018). Students will develop agency from creating small projects to engage the government, such as letter writing campaigns. Through these types of projects, students will be enabled to analyze the implications of local policies, and to examine various roles in the government that can support mitigation of climate issues. As they recognize the complexities of decision making at a government level, they can begin to see the emphasis of agency in greater world affairs.

The media sector is an effective vehicle for accessing information to build a knowledge base, as well as to share information with others. The media can provide a means for students to become engaged politically and publicly, help students to demonstrate local activism, and provide an outlet for applying the SDGs on a local scale. As we have already seen, the media was a significant climate-change leverage point for students at the Green School in Bali, the Sunnyside Environmental School in Oregon, and the Mountain Air Program. As students build knowledge at a local level, they develop incremental connections to global climate issues through news reports, internet sources, and other forms of media exposure.

\section{Part II}

\subsection{Curriculum Framework}

Our theory of action is as follows: if students understand the science behind climate change, recognize its impact on their local communities, and create communityoriented solutions leveraging the four sectors, then they can apply their learning into actions to address climate change issues. Ultimately, then, students can become collaborative leaders who prioritize climate change action.

The literature suggests that teaching climate issues is most effective when incorporated within multiple disciplines and aligned with learning goals such as the NGSS and SDGs, which highlight multidisciplinary concepts. As such, we chose participatory learning, community-focused learning, and interdisciplinary learning to align with student leadership development, knowing that students will demonstrate leadership skills through individual and community engagement, government, media, and corporate action. These practices help students gain cognitive, interpersonal, and intrapersonal skills, which will allow them to critically engage with local climate issues. The range of experiences offer students direct connections to how they can become autonomous actors not only in their future professional lives, but also as students.

In our climate curriculum model, we began by merging disciplines and the standards which students are expected to learn. Through combining learning from various subject areas, including science and social science, we developed learning objectives 
to strengthen students' cognitive and substantive knowledge, in addition to interpersonal and intrapersonal skills. Our pedagogical targets depend on communityfocused, interdisciplinary, and participatory learning practices, which we have found encourage student leadership development, practical application of learning, and are relevant to climate change topics.

\subsubsection{Curriculum Objectives}

We have summarized the learning objectives for elementary students as such:

1. Using informational texts, observe and understand the impact of climate change on your neighborhood.

2. Understand and explain the roles of these four sectors (media, government, the corporate sector, and individual/community engagement) on climate change, and how each sector can respond to climate change.

3. Collaborate to craft a message about the urgency of climate change issues using various media. With some guidance and support from adults, use technology to produce and publish your message.

4. Craft written and verbal arguments to convey a point of view supported by evidence.

5. From the perspective of a sector leader, imagine and design a solution to reduce the impact of climate change on humans in your neighborhood.

In addition to the learning and knowledge objectives outlined above, we intend to encourage students to reflect on their own values and moral dispositions toward the environment. As Reimers (2021) states, "[I]f education is to influence how we relate to the environment, it must activate our moral imagination, our capacity for ethical and critical thinking and not just dispense us with more facts." In combining substantive understanding of local climate issues with individual changes in mindsets and habits, students will be equipped to cooperate with others to influence the systems that exacerbate and accelerate climate change (Reimers, 2021). These changes in habits might be universal, such as using less water or taking public transportation to decrease carbon emissions, or contextual, such as lobbying local city councils to pass environmentally friendly regulations. According to Dr. Siva Kumani, Director General of the International Baccalaureate, it is crucial to set high expectations for students to meet: "If you give students the chance to make change once, it will be easier to form a habit for future positive actions" (Kumari, 2021). Although Dr. Kumani was primarily referring to the Creativity, Action, and Service (CAS) requirement of the IB diploma program, the same principle applies to the participatory learning component of our climate change curriculum. We considered this approach as we designed our pre-program and post-program survey questions, which measure the degree to which climate change is already a priority for students and their families. 


\subsubsection{Delivery Options}

Currently, the NGSS do not mention either the term "sustainability" or "climate change." Thus, it is increasingly urgent for schools to address these needs through locally created curricula, such as in those implemented in New Jersey. The decentralized approach to standards in the United States seeks to please every stakeholder in the education sector, so we aim to provide a more localized approach to the school system of Washington, DC. Many of the non-national curricula we saw were developed and distributed by independent organizations and nonprofit entities, which could result in varied implementations depending on teacher interpretation of the lesson. Though the lessons crafted by these third-party organizations were comprehensive and included interdisciplinary learning activities, we also want to implement these lessons in a manner that would result in school-wide buy in-rather than just participation from individual teachers, who may select these third-party lessons according to what they want to teach. Since we want teachers to collaborate across disciplines, we encourage teachers to convene as a teaching cohort to share instructional practices in a Peer Learning Community setting. This would create structured opportunities to enhance their professional knowledge on climate change issues, critical for the success of this program.

To disseminate our curriculum, we will likely need a partner to aid us in making curricula widely applicable to schools in different contexts. Whether through an independent publisher or a sponsor organization, we have considered the implications of expanding this curriculum to other schools outside of our client's school system. We are currently looking into developing more lessons, piloting our lessons through multiple environments, making lesson frameworks more flexible for educators in different contexts, and expanding the curriculum from grades 3-5 to K-12 to establish institutional changes and commitments to climate change beyond habit shifting. In addition to communicating with executives from the Zinn Education Project and Rethinking Schools Initiative, we have identified and considered other resource providers, including Envoys and the International Baccalaureate program, as potential partners to assist us in streamlining and publishing our curriculum to be distributed on a larger scale.

Current elementary science curricula (including at our partner school) are mostly knowledge-, rather than critical-thinking, based. From our analysis, climate change instruction is the most effective for third through fifth graders when it is delivered via a critical, collaborative framework (such as the Zinn Education Project). It is essential that students use these critical thinking skills to understand abstract topics, such as the greenhouse effect and greenhouse gases, anthropogenic phenomenon, and the consequences of human activities on ecology, society, culture, and economics in a developmentally appropriate manner is essential (UNESCO, 2017). Concerns of the impact of each of these topics on the world must be balanced with hope for the future on what students can do to make a difference in society. 


\subsection{Logical Framework}

Following our theory of action, we analyzed the factors that would be key in implementing our curriculum. In our work to strategically analyze the formation of our program theory and implementation theory, we created a logical framework to identify the latent assumptions and risks that underlie our program, our implementation plan, our achievement indicators, and our program evaluation tools.

\subsubsection{Assumptions and Risks}

Our theory of action is contingent on some assumptions that we have identified, namely time for teachers to teach our lessons, communication channels, and the willingness for teachers to collaborate across disciplines (ensuring student buy-in and participation within our shifting political climate). We also sought to mitigate these assumptions by collecting more data through pre-program surveys and qualitative research. Based on interviews with faculty, our partner school appears to be well-resourced and staffed. Though it has the resources and staff to implement our curriculum, we do assume that teachers would have time and ability to pilot a program during the pandemic, where most teaching is virtual or scaled back. We have talked to teachers who are enthusiastic about the program, but change also requires teachers who have the time to be able to coordinate and collaborate. After all, our curriculum requires interdisciplinary instruction and collaborative evaluation (such as portfolios and anecdotal data collection to assess student growth). To address this assumption, we intend for teachers to share the workload of this curriculum due to the interdisciplinary nature of the content. Indeed, we expect teachers to collaborate with each other for instruction and assessment, but this collaboration would also lead to creation of an authentic learning community across classrooms.

The method of learning, whether virtual or in-person, brings us to another assumption; student buy-in. We talked to teachers who are willing to offer a climate workshop using one of our lessons to students and gauge student interest. Otherwise, we would measure student buy-in within our curriculum by using periodic surveys. Since the curriculum is student-driven and contingent on participants continuing their involvement and interest in climate leadership, it is key to measure whether students are enthusiastic in their participation in this curriculum. Finally, we assume with the shift in national leadership, this school and others might be more willing to invest in a curriculum explicitly focused on climate change. Especially in our nation's capital, there may be a higher connection to the policies endorsed by Biden's Presidential administration. 


\subsubsection{Implementation Plan}

Initially implementing our program within our partner school, we will test how the curriculum works in building leadership and civic awareness towards climate change mitigation in elementary students. While piloting the curriculum, we will also reach out to other informal platforms to build the capacity of the curriculum for future scalability. After evaluating the implementation effects of the curriculum within our partner school, one that is well-resourced and highly innovative, we will adjust the scalability implications. With context adaptation ideas provided, we aim to have more schools adopt this curriculum.

Step 1: Our first step in implementing our climate change curriculum is to earn buy-in from school administrators and teachers. This must be accomplished through the following tasks: presenting the overall objectives to the school administration team to confirm their interest and decide channels for implementation, presenting the curriculum and lesson plan template to teachers to hear their feedback and ideas, and involving science teachers from middle schools, high schools, and universities (where climate change is well covered) for feedback of climate change instruction in elementary school.

Step 2: The next step is to assemble a team, which requires choosing teachers to pilot the program for the school year (whether this involves incorporating climate change education into the prescribed classroom curriculum or engaging extracurricular programs like science clubs) and expanding the team to scale the curriculum to other grade levels in following years. Members of the pilot team can act as mentors or instructional advisors for teachers implementing the curriculum in later school years.

Step 3: This step requires composing teacher development. For teachers to be successful, we propose surveying teachers to understand their current knowledge of content within the curriculum. This can lead to the creation of a Peer Learning Community for program teachers to congregate in a space for professional development from professors at local universities, speakers, and local workshops. In addition, teachers who piloted the program can provide instructional leadership to their peers.

Step 4: The following step is pilot implementation, during which teachers will complete the following tasks: collaborate with pilot science teachers to determine projects and capstone lessons, incorporate curriculum activities into classroom lesson plans, test curricular activities and ideas in their pilot class, document student learning (ex. photos of students' participation, projects), and work with students to publish their projects.

Step 5: After implementing instruction and curricular activities, educators will assess students' learning outcomes in the pilot classes. Teachers will evaluate students' learning outcomes in science knowledge, four-sector knowledge, leadership skills, and collaborative skills through project observations, observe students' behavior changes in living sustainably, and survey parents and caregivers to measure their changes of awareness, sustainable habits, and climate-friendly actions at home. 
Step 6: To gauge the program's effectiveness, school leaders and teachers will need to evaluate the implementation of the curriculum and adapt it as needed. The tasks necessary to complete this step will include interviewing pilot teachers to receive feedback on curriculum and resources, interviewing students for feedback on learning outcomes and learning experiences, collecting evidence of best practices, and updating the curriculum and learning activities based on feedback.

Step 7: Finally, we outlined a step to scale the curriculum within the school. Teachers will share student projects and relay their takeaways from the pilot classes across the elementary school to expand buy-in, discuss whole-school implementation with the elementary school administration team, and identify best practices through qualitative and quantitative data collection. Teachers and school leaders will also adopt modules of the curriculum to align with other programs at the school, such as environmental extracurricular clubs, upper elementary environmental education courses, and the experience to develop leadership attributes including communication, empathy, vision, and potential to influence.

\subsubsection{Achievement Indicators and Evaluation}

Our curriculum is designed to support students to become leaders, who will be able to prioritize climate action within their communities. We will know our curriculum's long-term success if students within the program engage in the four sectors to drive community impact in the future. Whether through policy changes, participation in climate-focused action movements (such as Fridays for Future and the Sunrise Movement), climate-driven media engagement, or driving eco-friendly business practices, we aim for students to continue climate-conscious behavioral habits and develop leadership skills regarding climate issues throughout their time at the school. These behaviors directly connect to our theory of change, as our implementation theory encompasses activities to drive student outcomes.

In the short term, we decided to keep program measurement aligned to activities that teachers at the school already do, so we can maximize their time and evaluate our curriculum as the program progresses. Our achievement indicators for students and curriculum evaluation use similar methods of assessment to that of project-based learning. We will rely on teachers participating in the program, who can reflect periodically and evaluate the curriculum by using surveys. Pre-program and postprogram surveys will be especially effective in gauging whether teachers believed the curriculum to be effective and successful. By tracking student data, including attendance, student work (including portfolios, writing samples, and assessments), and student participation, we can measure the outputs of our curriculum and evaluate whether our curriculum is effectively producing student leaders who prioritize action on climate change. Since our program is also compatible with CCSS, NGSS, and the SDGs, which teachers are familiar with at the school, we can also create rubrics and assessments that measure standards-aligned student achievement, as well. 
Ultimately, we will deem this program a success if students fully engage with the lessons and produce work that shows they have internalized these lessons, as well as if teachers and administrators reflect positively on their involvement and implementation of the curriculum prior to and after the program. Administrators may have varying perceptions of education priorities, particularly within the pandemic, but in the long term our curriculum helps develop students who live into the values that the school exemplifies. Knowing how children can inform and influence the knowledge, attitudes, or behaviors related to climate change of their parents, we also want to measure our curriculum's impact on students' parents and caregivers via surveying (Lawson et al., 2019). Our pre-program and post-program surveys for students, teachers, and students' caregivers have already given us valuable information about stakeholders' attitudes toward climate change, and we look forward to seeing whether and how our curriculum impacts survey responses after we complete the curriculum.

Numerous studies have shown that youth are increasingly concerned about climate change and want to prioritize learning more about it. Some studies indicate that students feel it is a more important subject than traditional school subjects (Magas, 2020; Children want, 2011). We confirmed this through student and caregiver surveys at our partner school. On a scale of 1-10, with 1 being "not important at all" and 10 being "highly important," we observed a 20-point difference between students and their caregivers who viewed climate change as a higher priority in the 9 and 10 range. Ultimately, students rated overall significantly higher rankings for the importance of learning about climate change. Therefore, there is potential for more students to influence their parents' ideas and urgency about the topic. We inquired about other aspects related to our curriculum such as environmental stewardship, global awareness/citizenship, service learning, writing, and collaborative projects, and skills in our survey as well.

We posed similar wonderings in a survey to an upper elementary class at our partner school (using a non-nationally representative sample) and found that $87.5 \%$ of the students surveyed ranked climate change as a 9 or 10 out of 10 in importance, and $96.8 \%$ of the students ranked it at 7 or higher. When ranking reading skills, $78.2 \%$ of students rated them as a 9 or 10 , and $91.6 \%$ of students ranked reading skills at 7 or higher. Mathematical problem solving was viewed slightly higher, with $75 \%$ of the students ranking math at a 9 or 10 , and $91.6 \%$ of the students viewing math skills as a 7 or above in importance. Climate change still ranked higher overall, confirming that climate change is of high interest to the students surveyed.

After considering how intergenerational learning between students and parents can change mindsets, we decided to survey parents as well (Lawson et al., 2019). Compared to $78.2 \%$ of students, $94.4 \%$ of parents viewed reading skills as a 9 or 10 out of 10 , and $100 \%$ of parents ranked reading above a 6 on our scale. Compared to $75 \%$ of students, $83.4 \%$ of parents viewed math problem solving skills as a 9 or 10 on our scale, and $100 \%$ ranked it as 7 or above. The largest difference by far was seen in perceptions of climate change; while $87.5 \%$ of students prioritized climate change, only $66.7 \%$ of parents ranked climate change education at a 9 or 10 . However, $100 \%$ of parents did rank it as a 7 or above. There was a 20-point difference between 
students and parents who viewed climate change as a higher priority in the 9 and 10 range, with students rating overall higher rankings for climate.

To effectively build teacher knowledge on specific issues related to our curriculum through professional development, we surveyed teachers involved in the initial curriculum pilot. According to teacher responses at our partner school, they feel confident building leadership competencies, participatory learning, and project-based learning. Conversely, teachers reported needing more support in policy creation steps, Model UN structure, and knowledge of climate refugees. They would therefore need more training in these areas, and of course other school contexts would need to identify the capacity of their own teachers and staff. Other areas where professional development could be helpful are in local climate issues, the greenhouse effect, and anthropogenic phenomena.

\subsection{Scalability}

We considered the scalability of our program outside of the context of our partner school, as well. Our niche reform reflects a need to address climate change and leadership within the context of the school by including multiple entry points. Yet our research shows a much broader need for participative, community-based, leadership-focused climate change curriculum content within other elementary schools extending beyond the Washington, DC area throughout the United States. To address this larger, more systemic problem, we have identified implications and applicable approaches to design a curriculum reform that would offer our curriculum to schools on a wider scale.

Our most prevalent barriers toward systemic scalability include limited teacher autonomy and capacity within other schools, limited school resources, limited school, and community cultural buy-in, and varieties between geographical contexts. Though school resource levels and teacher autonomy are critical considerations, we see geographical contexts and political landscapes as the most significant barriers towards adopting this climate change curriculum; a school community in liberal-leaning Washington D.C. that regularly witnesses the impacts of sea level rise may be more likely to buy-in to this program, but a school in rural, conservative Wisconsin may not due to the lack of visibility of climate change effects and polarized nature of climate change in the United States (Hornsey et al., 2016; Veloz et al., 2012). Given this concept, ideology and geographic context may likely be a hindrance in global adoption of climate change curricula as well.

After piloting the curriculum through in-class lessons and extracurricular science clubs, feedback helps upgrade it beyond that of a highly resourced environment with high teacher autonomy. In settings with limited teacher autonomy and capacity, informal learning resources such as science clubs, educational videos, or book clubs provide entry points to adopt the curriculum outside the classroom. Another consideration includes professional training on best teaching practices, which should be 
collected from piloted experiences and a developed package of resources. Policymakers, the public, and other climate change institutions can promote national standards on climate change education in elementary schools and provide potential to expand from niche reform to systemic change. Scaffolded teacher co-creation occurs through a framework to adapt lessons to the student needs, school resources, and differentiated activities within a school context.

In environments with limited school resources or cultural buy in, collaboration is essential. Differentiated climate change packages for high and low-resourced schools developed with science teachers match the school's vision and educational priorities. Funding potential arises through partnerships with organizations supporting climate change. Partnering with researchers to develop locally relevant curriculum content supports contextually driven climate change education. Incorporating climate change leadership and competency into twenty-first century skills could provide an entry point for global educational institutions to encourage schools to adopt the curriculum. We have seen in Chaps. 2 and 3, referencing India and Egypt, the eagerness of countries around the world to incorporate twenty-first century skills in education reforms, and we think the next step is to channel twenty-first century skill-building to address the realities and threats of climate change.

Ultimately, we are hopeful that our research and work to pilot this curriculum at our partner school provides a complete, coherent, and compelling argument to implement a system-wide shift to include climate change curriculum within the United States and beyond. In addressing funding for our curriculum, it can be said that its benefits expand beyond school resources. The curriculum is an efficient and costeffective measure to address climate change issues, by investing in student action and their influence on parents, community, and beyond. In examining the impact of the pandemic on government priorities, many areas are shifting funding to issues related to COVID-19 and reducing the fiscal resources devoted to climate change (United Nations Environmental Program, 2020). Our curriculum presents an investment in the future: students are empowered to immediately apply their knowledge to projects of activism and community engagement thus raising their voice and impact beyond the school walls.

\subsection{Conclusion}

Despite the slow nature of education reform, the pressing threats of climate change will not abate. Knowing our students will be the ones facing the ramifications of our changing climate, within this curriculum we are proposing a radical shift in the way we frame education to the leaders of tomorrow. Children are more capable than we realize, and we have seen powerful examples of young people leading movements to act on climate change. Children are more open to showing concern and a desire to mitigate climate change; the research shows that using a successful climate change curriculum, families will have more conversations about related issues, and begin to make changes to their household practices (Lawson et al., 2019). We need to 
counterbalance the worries we have for our world with a sense of hope in our future leaders; children are acutely aware and interested in climate change issues, so it is up to school leaders to harness this interest and channel it into action. As John Dewey says, "If we teach today's students as we taught yesterday's, we rob them of tomorrow."

To inspire future change, we must be tenacious. We must try innovative approaches, novel curricula, and new objectives for students. It is only through this tenacity that we will inspire students to take an active role in addressing climate change moving forward-otherwise we will, in fact, rob them of tomorrow.

Acknowledgements We would like to extend our deepest gratitude to the countless individuals who provided feedback at different levels of writing this chapter. We appreciate Dr. Fernando Reimers for his support and enthusiastic leadership, as well as Alysha Banerji, Uche Amaechi, and Margaret Wang for their keen and critical eyes and input. Thank you to our partner school for giving us the opportunity to pilot our ideas and work closely with staff. We are also grateful to the Zinn Education Project for providing inspiration on how to scale our curriculum. Thank you to Dr. Siva Kumari, who expertly provided key insights to us. Finally, thank you to our supportive classmates and peers, especially for the feedback in the final revisions of this chapter.

\section{References}

Arenstam Gibbons, S. J., Nicholls, R. J. (2006). Island abandonment and sea-level rise: An historical analog from the Chesapeake Bay, USA. Global Environmental Change, 16(1), 40-47. https://doi. org/10.1016/j.gloenvcha.2005.10.002

Australian Curriculum, Assessment, and Reporting Authority (ACARA). (2020). Cross-curriculum priority: sustainability. Australian Curriculum. Retrieved from https://www.australiancurri culum.edu.au/f-10-curriculum/cross-curriculum-priorities/sustainability/.

Bassetti, F. (2019, May 22). Environmental migrants: Up to 1 billion by 2050. Climate Foresight. Retrieved from https://www.climateforesight.eu/migrations-inequalities/environmentalmigrants-up-to-1-billion-by-2050/

Bigelow, B. (2020). We need to ask our students to dream and dream big. Rethinking Schools. https://rethinkingschools.org/articles/we-need-to-ask-our-students-to-dream-and-to-dream-big/.

Chesapeake Bay Foundation, (n.d.). Geography and facts. Retrieved September 21, 2020, from https://www.cbf.org/about-the-bay/chesapeake-bay-watershed-geography-and-facts.html\# overview.

Chesapeake Bay Foundation. (2020). Shellfish aquaculture. Chesapeake Bay Foundation. Retrieved from https://www.cbf.org/issues/fisheries/shellfish-aquaculture.html.

Climate Central. (2014, September). Washington, DC and the surging sea: A vulnerability assessment with projections for sea level rise and coastal flood risk. Surging Seas: Sea Level Rise Analysis by Climate Central. Retrieved from https://sealevel.climatecentral.org/uploads/ssrf/DC-Rep ort.pdf.

Children want to learn about the environment, survey finds. (2011, September 20). The Guardian. Retrieved December 10, 2020, from https://www.theguardian.com/environment/2011/sep/20/chi ldren-learn-environment-co-operative.

Crossley-Frolick, K. A. (2010). Beyond Model UN: Simulating multi-level, multi-actor diplomacy using the Millennium development goals. International Studies Perspectives, 11, 184-201. 
District of Columbia. (n.d.). Climate Ready DC. Retrieved September 21, 2020, from https://doee. dc.gov/sites/default/files/dc/sites/ddoe/service_content/attachments/CRDC-Report-FINALWeb.pdf.

Development Goals. Retrieved October 11, 2020, from https://www.un.org/sustainabledevelop ment/sustainable-development-goals/.

Eccles, J. (1999). The development of children ages 6-14. The Future of Children, 9, 30-44.

Erbil, D. G., \& Kocabaş, A. (2018). Cooperative learning as a democratic learning method. Journal of Research in Childhood Education, 32(1), 81-93.

Fenston, J. (2019, September 17). Here's how climate change is going to affect the D.C. area. DCist. Retrieved from https://dcist.com/story/19/09/17/climate-change-is-making-d-c-weatherwarmer-wetter-and-wilder/.

Foss, A. W., \& Ko, Y. (2019). Barriers and opportunities for climate change education: The case of dallas-fort worth in texas. The Journal of Environmental Education, 50(3), 145-159.

Friends of the Rappahannock. (2015). Students build oyster reef and living shoreline in Urbanna. River friends. Retrieved from https://riverfriends.org/students-build-oyster-reef-and-living-sho reline-in-urbanna/.

Haack, K. (2008). UN studies and the curriculum as active learning tool. International Studies Perspectives, 9, 395-410.

Heifetz, R. A., Heifetz, R., Grashow, A., \& Linsky, M. (2009). The practice of adaptive leadership: Tools and tactics for changing your organization and the world. Harvard Business Press.

Holdsworth, R. (2019). Student agency around climate action: A curriculum response. Ethos, 27(3), 9.

Hornsey, M. J., Harris, E. A., Bain, P. G., \& Fielding, K. S. (2016). Meta-analyses of the determinants and outcomes of belief in climate change. Nature Climate Change, 6(6), 622-626.

Kabisch, N., Korn, H., Stadler, J., \& Bonn, A. (2017). Nature-based solutions to climate change adaptation in Urban areas: Linkages between science, policy and practice (Theory and Practice of Urban Sustainability Transitions). Cham: Springer Open.

Kirwan, M., \& Megonigal, J. (2013). Tidal wetland stability in the face of human impacts and sea-level rise. Nature, 504, 53-60. https://doi.org/10.1038/nature12856

Kumari, S., (2021, January 21). Expert Discussant. In F. Reimers (Chairs), Educating students to address climate change. [Panel presentation] Global Education Conference.

Jamal, T., \& Watt, E. M. (2011). Climate change pedagogy and performative action: Toward community-based destination governance. Journal of Sustainable Tourism, 19(4/5), 571-588.

Jesuit \& Endless. (2018). Model United Nations and experiential learning: an assessment of changes in knowledge and attitudes. Journal of Social Studies Education Research, 9(4), 198-213.

Lawson, D. F., Stevenson, K. T., Peterson, M. N., Carrier, S. J., Strnad, R. L., \& Seekamp, E. (2019). Children can foster climate change concern among their parents. Nature Climate Change, 9(6), 458-462.

Leatherman, S. P., Chalfont, R., Pendleton, E. C., McCandless, T. L., Funderburk, S. (1995). Vanishing lands: Sea level, society and Chesapeake Bay. U.S. Fish and Wildlife Service, Chesapeake Bay Program. https://www.fws.gov/slamm/VanishingLandsSeaLevelSocietyandChesape akeBay2.pdf.

Magas, M. (2020, November 22). Alberta youth want better education on climate change, survey concludes. The Energy Mix. https://theenergymix.com/2020/11/22/alberta-youth-want-bettereducation-on-climate-change-survey-concludes/.

Maloney, K. O., Krause, K. P., Buchanan, C., Hay, L. E., McCabe, G. J., Smith, Z. M., et al. (2020). Disentangling the potential effects of land-use and climate change on stream conditions. Global Change Biology, 26(4), 2251-2269.

McIntosh, D. (2001). The uses and limits of the model United Nations in an international relations classroom. International Studies Perspectives, 2, 269-280.

Monroe, M. C., Plate, R. R., Oxarart, A., Bowers, A., \& Chaves, W. A. (2019). Identifying effective climate change education strategies: A systematic review of the research. Environmental Education Research, 25(6), 791-812. 
Najjar, R. G., Pyke, C. R., Adams, M. B., Breitburg, D., Hershner, C., Kemp, M., et al. (2010). Potential climate-change impacts on the Chesapeake Bay. Estuarine, Coastal and Shelf Science, 86(1), 1-20.

National Ocean Service. (2020). Is sea level rising? National Oceanic and Atmospheric Administration. Retrieved from https://oceanservice.noaa.gov/facts/sealevel.html.

Next generation science standards for states by states. (n.d.). Get to Know the Standards. https:// www.nextgenscience.org/get-to-know

Orth, R. J., Dennison, W. C., Lefcheck, J. S., Gurbisz, C., Hannam, M., Keisman, J., et al. (2017). Submersed aquatic vegetation in Chesapeake Bay: Sentinel species in a changing world. Bioscience, 67(8), 698-712.

Pellet, Scruton, R. (2020). Going green: integrating ecosystems and climate change into our language curriculum. Use of English, 71(2), 85-90.

Perkins, K. M., Munguia, N., Moure-Eraso, R., Delakowitz, B., Giannetti, B. F., Liu, G., et al. (2018). International perspectives on the pedagogy of climate change. Journal of Cleaner Production, 200, 1043-1052.

Reimers, F. M. (2021). Education and climate change: The role of Universities. Springer.

Reimers, F. M. (2020). A cultural perspective and global education. In Educating Students to Improve the World (pp. 31-52). Springer, Singapore.

Roychoudhury, A., Shepardson, D. P., Hirsch, A., Niyogi, D., Mehta, J., \& Top, S. (2017). The need to introduce system thinking in teaching climate change. Science Educator, 25(2), 73-81.

Samenow, J. (2014, September 16). Climate expert: "Washington, DC faces significant risk of record high floods". Washington Post. Retrieved from https://www.washingtonpost.com/news/ capital-weather-gang/wp/2014/09/16/climate-expert-washington-d-c-faces-significant-risk-ofrecord-high-floods/?arc404=true.

Seely, M. (2019, June 9). Rising tide of students puts climate change in the classroom. New York Times. Retrieved from https://www.nytimes.com/2019/06/09/us/portland-climate-change.html.

Siegner, A., \& Stapert, N. (2020). Climate change education in the humanities classroom: A case study of the Lowell school curriculum pilot. Environmental Education Research, 26(4), 511-531.

Smith, G. A., \& Sobel, D. (2014). Place-and community-based education in schools. Routledge.

State of New Jersey Department of Education. (December 2020.) 2020 New Jersey Student Learning Standards Science Kindergarten through Grade 12. https://www.nj.gov/education/cccs/2020/ NJSLS-Science.pdf.

Stuart, T., Stuart, M., \& Kimball, C. (2017). Wild and thoughtful innovation. National Association of Independent Schools. Retrieved from https://www.nais.org/magazine/independent-school/spr ing-2017/wild-and-thoughtful-innovation/.

Sustainable Development Goals Partnership Platform. (n.d.). SDG good practices. https://sustainab ledevelopment.un.org/partnership/browse/.

Teach Climate Justice Campaign. (n.d.). Zinn Education Project. Retrieved on December 10, 2020 from https://www.zinnedproject.org/campaigns/teach-climate-justice.

The Green School. (2020). Green projects hub. The Green School Bali. Retrieved from https:// www.greenschool.org/bali/support-us/green-projects-hub/.

United Nations. (n.d.). Take action for the sustainable development goals. Sustainable.

United Nations Environment Program (2020, December 9). Emissions Gap Report 2020. Retrieved December 10, 2020 from https://www.unep.org/emissions-gap-report-2020.

UNESCO. 2017b. Education for sustainable development goals: Learning objectives. Paris: UNESCO. https://unesdoc.unesco.org/ark:/48223/pf0000247444.

UN Environment Programme. (n.d.). Why do the sustainable development goals matter? Retrieved from https://www.unenvironment.org/explore-topics/sustainable-development-goals/ why-do-sustainable-development-goals-matter.

U.S. Global Change Research Program. (2018). Fourth national climate assessment: Chapter 18: Northeast. https://nca2018.globalchange.gov/chapter/18/.

Van Zee, E. H., Roberts-Harris, D., \& Grobart, E. (2016). Ways to include global climate change in courses for prospective teachers. Journal of College Science Teaching, 45(3), 28. 
Veloz, S., Williams, J. W., Lorenz, D., Notaro, M., Vavrus, S., \& Vimont, D. J. (2012). Identifying climatic analogs for Wisconsin under 21st-century climate-change scenarios. Climatic Change, 112(3), 1037-1058.

Watts, N., Amann, M., Arnell, N., Ayeb-Karlsson, S., et al. (2019). The 2019 report of the lancet countdown on health and climate change: ensuring that the health of a child born today is not defined by a changing climate. The Lancet. 394(10211), 1836-1878. ISSN 0140-6736. https:// doi.org/10.1016/S0140-6736(19)32596-6

White, E. S. (2012). Civic engagement in the upper elementary grades: An examination of parent and teacher practices and children's civic identity (Order No. 3508228). Available from ProQuest Dissertations \& Theses Global. (1017882762). Retrieved from http://search.proquest.com.ezpprod1.hul.harvard.edu/docview/1017882762?accountid=11311.

Yorio, K. (2019). Youth to educators: teach. School Library Journal, 10-11.

Kathryn Bauman-Hill is a longstanding educator deeply involved in equity work, culturally responsive teaching practices, and creating accessible spaces for all students. Her educational passions include developing an environment where students engage in critical service learning, social justice advocacy, and climate change leadership through multidisciplinary experiential formats. She is an elementary and early childhood head of school in Washington, DC and is pursuing a Masters in School Leadership at Harvard Graduate School of Education.

Susan (Congcong) Dai has been working in after-school learning institutions for the last decade doing ESL teaching, teacher training and management, product management, learning center operation, and teacher HR. Apart from teaching language arts, she is also passionate about developing leadership skills and global citizenship awareness in young children. With expertise in pulling resources to support better teaching, she is now working on family consultation of ESL learning and continuing exploring the climate curriculum in China. She completed her graduate studies at the Harvard Graduate School of Education in Education Policy and Management.

Arcadia Payne has experience in the field of education as a teacher, a policy analyst, and a consultant. Arcadia is especially passionate about the intersections of education, climate change, and migration, including education in emergencies and environmental education. She earned honors degrees in Political Science and International Studies from the University of Utah and a Masters' of International Education Policy from the Harvard Graduate School of Education.

Open Access This chapter is licensed under the terms of the Creative Commons Attribution 4.0 International License (http://creativecommons.org/licenses/by/4.0/), which permits use, sharing, adaptation, distribution and reproduction in any medium or format, as long as you give appropriate credit to the original author(s) and the source, provide a link to the Creative Commons license and indicate if changes were made.

The images or other third party material in this chapter are included in the chapter's Creative Commons license, unless indicated otherwise in a credit line to the material. If material is not included in the chapter's Creative Commons license and your intended use is not permitted by statutory regulation or exceeds the permitted use, you will need to obtain permission directly from the copyright holder. 